\title{
The Fate of Newborn Screening Blood Spots
}

$\mathrm{T}$ hrough much of the mid-1990s, a passionate debate raged among medical geneticists, pathologists, ethicists, and legal scholars regarding ownership, potential uses, and disposition of residual, stored, or archival human tissue specimens. Primarily at issue was whether a patient who had undergone a biopsy or surgery (or even simple phlebotomy) for diagnostic or therapeutic purposes had any right to determine or restrict subsequent nonmedical uses of their specimen for research, epidemiologic study, quality control of other patients' tests, or even commercial manufacture. Of special concern was the conduct of genetic research on such specimens, because the patient DNA contained therein could theoretically yield current and future information about the individual that goes far beyond the original clinical indication for collecting the sample. The two sides of the debate broke down generally into those who wanted to protect patient autonomy and privacy above all and those who felt that the inestimable and irreplaceable value of these millions of specimens for investigation of disease mechanisms superceded most patient property rights and the remote (as they saw it) risk of harm from such uses. Many professional groups and governmental agencies weighed in on the debate, and whole books were written about it (1). In the end, a series of compromise guidelines were promulgated, including recommendations for more specific informed consent, procedures for de-identifying specimens, and enhanced oversight by institutional review boards.

After the relative calm of the $15 \mathrm{y}$ since that time, we now find ourselves enmeshed in a similar debate surrounding a rather different type of specimen: the newborn screening blood spot. As everyone in pediatrics knows well, these dried blood spots on filter cards are collected on all newborns and sent to state-contracted laboratories to perform screening tests for a panel of at least 29 disorders, most of which are metabolic diseases such as phenylketonuria that require early presymptomatic treatment but also include additional disorders such as cystic fibrosis and sickle cell disease in many states (2). For backup and quality assurance, more spots are collected than are actually used for the screening tests, and the residual cards are retained by many states for years or indefinitely. Just as was true for the archival tissue specimens, these blood spots, representing more than 4 million babies born in the United States each year, are proving of tremendous value in epidemiologic surveys, quality improvement of the screening tests themselves, and development of new and future tests for other diseases. And just as was the case for the tissue samples, some ethicists and advocacy groups are calling for the destruction of all these filter cards after the newborn screening tests are complete, on the grounds that their retention and use has not followed standard informed consent guidelines for other types of research on residual specimens. The issue has now reached the legal system, with a lawsuit filed last year in federal court by a group of parents against the Texas Department of State Health Services.

In response, the American College of Medical Genetics has issued a position statement (3) reiterating the necessity for retention and access to these specimens for the continued success, assessment, and future growth of newborn screening programs. In addition, the statement points out that there is no historic basis for fears of abuse and privacy violations; that for most studies, the specimens are anonymized or de-identified; and that any investigation going beyond that would require standard informed consent. Moreover, the case is made that these blood spots represent "a valuable national resource that can contribute significantly to the health of our children." Considering the negligible risk for harm in this setting against the huge potential benefit, it is hard to argue with that. Still, the door has now been opened, and pediatricians working in the newborn nursery can probably expect to field increasing questions from parents as their babies undergo the formerly innocuous and little-noticed heel-stick procedure.

Note added in proof. In an unfortunate decision issued since this article went to press, a federal court in San Antonio has sided with the plaintiffs in the case and ordered the destruction of approximately 5 million residual newborn screening blood spots that were routinely collected and retained by the State of Texas without specific informed consent. The precedent set by this legal settlement bodes ill for similar actions in other states. - Wayne W. Grody and R. Rodney Howell

\section{REFERENCES}

1. Weir RF, Olick RS 2004 The Stored Tissue Issue: Biomedical Research, Ethics, and Law in the Era of Genomic Medicine. Oxford University Press, New York, 366 pp

2. American College of Medical Genetics 2006 Newborn screening: toward a uniform screening panel and system. Genet Med 8:1S-252S

3. American College of Medical Genetics Board of Directors 2009 Position statement on importance of residual newborn screening dried blood spots. Available at: http:/ www.acmg.net/StaticContent/NewsReleases/Blood_Spot_Position_Statement2009. pdf. Accessed December16, 2009 